\title{
Unidade de Acolhimento Adulto: um olhar sobre o serviço residencial transitório para usuários de álcool e outras drogas
}

\author{
Adult Reception Unit: a look at the transitional residential service for \\ alcohol and other drug users
}

Amanda Lima Macedo de Almeida', Marize Bastos da Cunha'

DOI: $10.1590 / 0103-1104202112808$

RESUMO Esta pesquisa teve como objetivo dar visibilidade às Unidades de Acolhimento Adulto (UAA), com intuito de fornecer maior qualidade e contextualização à produção de conhecimento sobre elas. Trata-se de um estudo de caso exploratório sobre uma UAA localizada no estado do Rio de Janeiro, um serviço de saúde de caráter residencial transitório destinado aos usuários de álcool e/ou outras drogas. Foram utilizadas para coleta de dados as técnicas de observação participante, levantamento documental e entrevistas abertas com usuários e profissionais. É apresentada descrição da estrutura desse serviço, do seu funcionamento e da relação com outros serviços e com o território onde está inserido. A partir dos resultados, pode-se afirmar que a UAA é um serviço de base territorial que segue a lógica da atenção psicossocial, considerando a subjetividade e o contexto de cada usuário, afirmando-se como modalidade de cuidado que se contrapõe à lógica de confinamento e proibicionismo das 'comunidades terapêuticas'. Também foi visto que a UAA possibilita mudanças nas formas de relação entre a comunidade e os usuários de substâncias psicoativas.

PALAVRAS-CHAVE Saúde mental. Redução de danos. Serviços públicos de saúde. Território sociocultural.

\begin{abstract}
This research aimed to give visibility to the Adult Reception Units (UAA), in order to provide greater quality and context to the production of knowledge about them. This study was carried out from an exploratory case study on a UAA, located in the state of Rio de Janeiro, a transitional residential health service for users of alcohol and/or other drugs. Participatory observation techniques, documentary surveys, and open interviews with users and professionals were used for data collection. A description of the structure of this service, its operation and the relationship with other services, and the territory in which it is inserted are presented. Based on the results, it can be said that Adult Reception Units are a territorial-based service that follows the logic of psychosocial care, considering the subjectivity and context of each user, affirming itself as a care modality that is opposed to the logic of confinement and prohibition of 'therapeutic communities'. It was also observed that the UAA allows changes in the forms of relationship between the community and users of psychoactive substances.
\end{abstract}

KEYWORDS Mental health. Harm reduction. Public health services. Sociocultural territory.

1 Fundação Oswaldo Cruz (Fiocruz), Escola Nacional de Saúde Pública Sergio Arouca (Ensp) - Rio de Janeiro (RJ), Brasil. amanda_alma@yahoo. com.br 


\section{Introdução}

A assistência à saúde para usuários de drogas é historicamente marcada por um olhar repressivo, tendo a internação como modo de tratamento e a abstinência como meta a ser alcançada.

No Brasil, as políticas públicas de saúde que assistem essa população são recentes. Apenas em 2002 foram instituídas pelo Ministério da Saúde, com a ampliação e a diversificação das ofertas em saúde para usuários de drogas. A concepção e as estratégias de prevenção passaram por algumas mudanças ao longo dos anos, a partir, principalmente, do movimento de redução de danos $\mathbf{1}^{\mathbf{1}, 2}$.

Em 2006, entrou em vigor a 'nova lei de drogas', Lei ${ }^{0} 11.343 / 06$, que trouxe como umas das principais disposições a prescrição de medidas para prevenção, atenção e reinserção social. A lei também estabelece punições de maneira diferenciada para aquele que utiliza a droga para consumo pessoal e aquele que fornece ou produz. Porém, foi mantido o aspecto de criminalização e repressão ao consumo e ao porte de drogas ${ }^{3,4}$.

Em meio a avanços e retrocessos, configurou-se um conflito no que diz respeito à atenção ao usuário de drogas: de um lado, a política proibicionista, que tem seu foco na substância tornada ilícita e se baseia em ações de repressão e criminalização; do outro lado, as políticas de redução de danos que, através de um conjunto de estratégias, objetivam a diminuição dos danos à saúde, sociais e econômicos relacionados ao consumo de álcool e outras drogas, sem necessariamente reduzirem seu consumo ${ }^{2}$.

Os embates seguiram recorrentes entre esses modelos, e, em 2019, a Lei Federal $n^{\circ}$ 13.840 altera a referida lei de 2006 , o que reforça o foco na abstinência, dedicando-se a tratar das modalidades de internação hospitalar e fortalecendo a ampliação das comunidades terapêuticas ${ }^{5}$.

Nos últimos anos, no âmbito da acelerada investida contra o Sistema Único de Saúde (SUS), no campo da saúde mental, foram apresentadas propostas de mudanças em sua política contrárias ao movimento da Reforma Psiquiátrica Brasileira. Algumas dessas alterações foram aprovadas na reunião da Comissão Intergestores Tripartite (CIT) ${ }^{6}$. É importante destacar que essas alterações ocorreram após uma votação rápida e sem debate público junto às esferas de controle social do SUS, desconsiderando o histórico, bem como a política de saúde mental construída coletivamente por quatro conferências nacionais de saúde mental e pela Lei $\mathrm{n}^{0} 10.216 / 2001^{7}$.

Outro grave episódio foi a reorientação da Política Nacional Sobre Drogas (PNAD), em 2018, com relação à direção da promoção da abstinência e ao financiamento de Comunidades Terapêuticas (CTs) com recursos também do Ministério da Saúde. Destacase que as CTs já vinham sendo financiadas no âmbito dos Ministérios da Justiça e do Desenvolvimento Social ${ }^{8}$.

O direcionamento de recursos provenientes do Ministério da Saúde para as CTs implicou redução de investimento na Rede de Atenção Psicossocial (Raps) já existente, aumentando seu sucateamento e impedindo a habilitação de novos serviços. Com efeito, a luta contra o investimento de recursos públicos em dispositivos que impõem restrições e exigem abstinência é um dos grandes desafios atuais da Reforma Psiquiátrica Brasileira9

Em muitas dessas CTs, em sua maioria de cunho religioso e/ou lucrativo, ocorre violação de direitos humanos. Elas têm o funcionamento baseado em ações morais e na imposição de abstinência, além de serem favoráveis a uma política de internação - posição contrária à da Reforma Psiquiátrica Brasileira, que defende a produção de um cuidado antimanicomial4,10. Vale apontar que a noção de antimanicomial refere-se ao cuidado em liberdade e está associada à luta pelos recursos que possibilitem as trocas sociais, contrapondo-se, portanto, às instituições de isolamento e exclusão, que acabam por objetificar os sujeitos ${ }^{11}$.

Em sua nota técnica, o Instituto de Pesquisa Econômica Aplicada (Ipea) indica 
o crescimento das CTs no Brasil, um dado que pode ser atribuído à persistente lacuna assistencial de serviços públicos voltados para os usuários de drogas ${ }^{\mathbf{1 2}}$. No entanto, também demonstra um projeto de poder das instituições religiosas no País, utilizando-se da questão das drogas para fortalecer a mercantilização de serviços assistenciais.

Neste sentido, em um contexto em que se ampliam as medidas que apontam para o desmonte do SUS, é fundamental ter maior conhecimento sobre os serviços oferecidos à população e os riscos envolvidos na perda de equipamentos que têm como direção do cuidado a atenção psicossocial e a redução de danos.

O presente estudo aborda um dos serviços de cuidado voltados para os usuários de drogas, criado no âmbito da Reforma Psiquiátrica, que não se expandiu de forma a atender às necessidades da população e é muito pouco conhecido: a Unidade de Acolhimento Adulto (UAA).

Instituída por meio da Portaria $n^{0} 121$, de 2012, a UAA oferece acolhimento a pessoas com necessidades decorrentes do uso de crack, álcool e outras drogas, tendo como foco ações orientadas para prevenção, promoção da saúde, tratamento e redução dos riscos e danos associados ao consumo de substâncias psicoativas. Configurando-se como um componente residencial transitório da Raps, visa a acolher voluntariamente e oferecer cuidados contínuos a usuários acompanhados por um Centro de Atenção Psicossocial (Caps), que estejam em situação de vulnerabilidade social e/ou familiar e que demandem um acompanhamento terapêutico e protetivo. Dessa forma, toda UAA deve estar referenciada a um Caps $^{13}$.

As unidades de acolhimento funcionam em duas modalidades: Unidade de Acolhimento Adulto (UAA), destinada às pessoas maiores de 18 (dezoito) anos, de ambos os sexos; e Unidade de Acolhimento Infanto-Juvenil (UAI), voltada para crianças e adolescentes, com idade entre 10 (dez) e 18 (dezoito) anos incompletos, de ambos os sexos ${ }^{13}$.

As UAAs são serviços de base territorial que seguem a lógica da atenção psicossocial, consideram a subjetividade e o contexto de cada usuário, bem como valoriza suas experiências de vida.

Lima e Yasui ${ }^{14}$, destacando a multiplicidade de sentidos que formam o território, convocam a pensá-lo como espaço, processo, relação e composição. Sendo assim, o território não se refere a um lugar estático, mas, sim, a um lugar ativo, dinâmico, repleto de inter-relações, construído cotidianamente, onde se realiza a vida coletiva. Por isso, um serviço de base territorial, no caso a UAA, não se refere apenas à sua área de abrangência.

A UAA, enquanto um serviço residencial transitório, configura uma modalidade de cuidado que se contrapõe à lógica de confinamento e proibicionismo das CTs, que vem avançando amplamente. A UAA, tendo em vista sua particularidade, garante direitos de moradia, convivência familiar e social. Assegura, ainda, o cuidado singularizado e em liberdade, incorporando os princípios da Reforma Psiquiátrica.

Com o objetivo maior de oferecer um retrato desse serviço, e contribuir, assim, para sua maior visibilidade, este estudo buscou responder às seguintes perguntas: como se dá a dinâmica de funcionamento da UAA? Como é sua relação com os outros serviços de saúde? Como é sua relação com o território onde está localizada?

\section{Material e métodos}

A pesquisa foi desenvolvida no período de setembro de 2018 a março de 2019 , como um estudo de caso único exploratório sobre uma UAA localizada no estado do Rio de Janeiro. A opção por esse desenho metodológico deu-se diante da necessidade de obter uma visão mais detalhada da unidade de saúde investigada, bem como para possibilitar a construção de hipóteses analíticas capazes de orientar trabalhos futuros ${ }^{15}$. Revelou-se, ainda, ser esse o método mais adequado à perspectiva principal do estudo de conhecer e dar visibilidade à 
estrutura e à dinâmica da UAA. Possibilita, ainda, a compreensão de uma organização ou comunidade, abrindo espaço a formulações teóricas mais gerais sobre regularidades do processo e estruturas sociais ${ }^{16}$.

No estudo, foram utilizadas técnicas da metodologia qualitativa, como levantamento documental, observação participante e entrevistas abertas com usuários e profissionais da unidade selecionada.

O levantamento documental foi realizado considerando-se os seguintes aspectos: organização da equipe; atividades internas; atividades no território; estrutura de reuniões de equipe; recursos materiais da unidade; relação com os Caps; relação com outras instituições; organização da rotina da unidade e normas de convivência; e perfil das pessoas que passaram pelo acolhimento. Foram consultados documentos internos da UAA: livro de ocorrências, atas de reuniões de equipe e 'censo diário', contemplando o período de agosto de 2013 a agosto de 2018.

A observação participante seguiu um roteiro que enfocou as seguintes questões: organização interna; discussão de caso; construção do Projeto Terapêutico Singular (PTS); dinâmica da unidade; atividades externas; relação com outras instituições; relação com a comunidade; situações de adversidades; relação entre a unidade e o usuário após o término de seu acolhimento. A observação também foi fundamental para uma interação prévia com a realidade dos possíveis participantes, antes da realização das entrevistas.

A seleção dos participantes para as entrevistas deu-se de forma a escutar os principais agentes sociais presentes em uma UAA. Na categoria usuários, foram incluídos aqueles que passaram períodos maiores de acolhimento e os que estiveram por períodos menores de acolhimento na unidade. Procurou-se agregar, ainda, diferentes gêneros e priorizar os usuários que tenham passado por outras formas de acolhimento institucional, como abrigamento ou internação. Quanto aos profissionais, buscou-se incluir participantes da equipe técnica e da equipe de apoio, que foram selecionados considerando: o critério de antiguidade na UAA (maior tempo e menor tempo de trabalho), moradia próxima ao território e trabalho anterior em outro serviço de saúde mental.

Além disso, estavam previstas entrevistas com familiares de usuários que já passaram pelo acolhimento na unidade, tendo em vista que são importantes na participação e parceria no cuidado e que também demandam atenção e cuidado dos serviços de saúde mental. Porém, devido a dificuldades em conseguir contato com familiares e ao prazo para a conclusão da pesquisa, não foi possível efetuar essas entrevistas.

Foram realizadas seis entrevistas, três com cada categoria de participantes, apoiadas por um roteiro aberto. No caso dos usuários, buscou-se conhecer: os motivos que levaram ao acolhimento; rotina na UAA; relação com profissionais de equipe e com os outros usuários; expectativas e avaliação quanto ao acolhimento; relação com o território; acesso a outros serviços de saúde, da assistência social, de educação, cultura e lazer durante o período em que estavam acolhidos. Quanto aos profissionais de saúde, o roteiro incluiu: indicação e entrada para acolhimento na UAA; rotina na unidade; manejo quanto ao uso de drogas; conclusão do acolhimento; articulação com outros serviços de saúde, assistência social, educação, cultura e lazer; ações para promoção de reinserção e reabilitação do acolhido; dificuldades na relação com o território.

Em uma primeira etapa, o material coletado na observação participante e no levantamento documental foi sistematizado tendo em vista eixos e categorias de análise que pudessem contribuir para responder às questões da pesquisa. Na análise das entrevistas, os relatos foram transcritos, organizados e relacionados aos dados já sistematizados. As informações geradas no segundo momento, em que os dados de todas as fontes estão incluídos, foram analisadas de forma a alimentar a discussão final do trabalho.

A pesquisa teve a aprovação do Comitê de Ética em Pesquisa da Escola Nacional de Saúde Pública Sergio Arouca - Ensp/Fiocruz, sob 
parecer 2.732.930, e do Comitê de Ética da Secretaria Municipal de Saúde do município onde está localizada a UAA estudada. Como estratégia de proteção e prevenção de riscos, foi garantido o anonimato dos participantes. A UAA, assim como sua localidade, não foi identificada, o que, de certa forma, limitou a divulgação de algumas análises do estudo, particularmente no que se refere à inserção da unidade no território. Refletir sobre os desafios da UAA em um território onde a milícia se destaca por sua presença era um dos objetivos iniciais da pesquisa. Contudo, a abordagem de tais desafios levaria à identificação da Unidade e colocaria os entrevistados em risco, haja vista o reduzido número de UAAs. Portanto, foi necessário priorizar o princípio e o cuidado ético e dar ênfase ao objetivo maior da pesquisa de conferir visibilidade à estrutura e à dinâmica de uma UAA.

\section{Resultados e discussão}

Considerando as proposições iniciais do estudo, resultados e discussão serão apresentados em torno de três eixos interligados: o espaço e seus agentes sociais; organização diária; e relação com o território.

\section{O espaço e seus agentes sociais}

A região onde a UAA estudada está localizada vem experimentando grandes transformações econômicas e sociodemográficas nos últimos 15 anos: a passagem de uma via expressa, a presença de programa de habitação federal, bem como de um programa municipal de habitação, sustentabilidade e urbanismo, que provocaram impactos na dinâmica do território.

No território, destaca-se a presença de grupos de milícia com interesses político e financeiro. Justificando sua intenção de oferecer a segurança da comunidade e combater o tráfico de drogas, tais grupos realizam a 'vigilância' da região, associada a práticas ilegais.

Nesse contexto de mudanças, em um território onde se destaca o poder da milícia, é que se implantam os serviços de atenção ao usuário de drogas. O Centro de Atenção Psicossocial Álcool e outras Drogas (Caps AD) foi inaugurado em 2012, enquanto as atividades da UAA se iniciaram em 2013. Fundamental destacar que parte dos desafios experimentados por esses serviços refere-se ao fato de estarem localizados em um território onde a milícia impõe seu poder.

A UAA está localizada próximo ao Caps $\mathrm{AD}$ ao qual é referenciada, o que favorece o contato e a troca entre os serviços. $\mathrm{O}$ espaço físico da unidade conta com uma parte externa composta por um jardim, várias árvores frutíferas, varanda e um gramado nos fundos. A área interna dispõe de uma casa de um andar, com amplas janelas, seis quartos, três banheiros, sala de televisão, copa, depósito, área de serviço, sala de administração, sala de jogos, sala de reunião, sala de equipe e quarto para descanso dos funcionários. Os quartos dos acolhidos têm de duas a três camas. Para preservá-lo como local mais privado para aqueles que o ocupam, é orientado aos usuários que não entrem nos quartos uns dos outros. Mas cada um entra e sai de seu próprio quarto no momento que desejar.

A equipe técnica é composta por um coordenador técnico, uma assistente social, uma enfermeira, uma psicóloga, um auxiliar administrativo e 16 profissionais de nível médio (plantonistas). Já a equipe de apoio inclui dois copeiros, quatro vigilantes patrimoniais e quatro auxiliares de serviços gerais.

Sobre o perfil dos usuários acolhidos, em cinco anos de funcionamento, a UAA estudada acolheu 245 pessoas, sendo $75,5 \%$ do sexo masculino e $24,5 \%$ do sexo feminino. Do total de usuários, $80 \%$ residem na mesma região em que a unidade está localizada, e $20 \%$ são oriundos de outras regiões do estado.

A UAA tem disponibilidade de 15 vagas, e não há limite para a quantidade de vezes de acolhimento de um usuário. Levando-se em consideração que uma mesma pessoa pode ser acolhida mais de uma vez, a unidade realizou 523 acolhimentos, de 2013 a 2018. A média 
de tempo de permanência é de 34 dias, e a média de idade dos usuários é de 37 anos. Do total de acolhimentos, apenas 16 duraram mais de seis meses.

Tendo como referência a leitura psicossocial dos lugares apresentada por Fischer ${ }^{17}$, a UAA se aproxima de um espaço residencial, apresentando, também, características de espaço institucional. A ideia de casa pode se expressar de diversas formas, mas tem como característica fundamental ser um espaço de proteção dos perigos exteriores.

A UAA enquanto casa assume aspectos de espaço pessoal, um lugar privilegiado, objeto de investimento afetivo, referência e pressupõe certa estabilidade. $\mathrm{O}$ espaço de habitação é onde se encontra o sentimento de identidade e também é um lugar de socialização. Isso se traduz, por exemplo, no esforço de manter acomodações que garantam a privacidade dos acolhidos e, ao mesmo tempo, possibilitem práticas coletivas e uma rede de serviços e de relações, fundamentais ao processo de cuidado em liberdade.

A fim de garantir a singularidade de cada usuário, os quartos têm poucas camas, e os acolhidos dispõem de armários individuais para guardar seus pertences. Nos quartos, foi observada a influência de cada acolhido no espaço, por meio da organização, da arrumação e da decoração. Outras características da UAA que permitem a apropriação do espaço são as atividades diárias que os acolhidos realizam no ambiente e a gestão compartilhada das áreas coletivas da casa.

\section{Organização diária}

O acolhimento dos usuários é indicado exclusivamente pela equipe do Caps de referência. Os Caps ficam responsáveis pelo PTS e seu acompanhamento, pelo planejamento da saída (em parceria com a UA) e pelo seguimento do cuidado ${ }^{18}$.

Na UAA estudada, o processo de início do acolhimento ocorre a partir de uma avaliação conjunta. O Caps de referência do usuário entra em contato com a equipe da UAA para apresentar o caso e as questões pertinentes a serem trabalhadas. Em um segundo momento, uma vez que o caso já foi discutido, havendo consenso entre as equipes quanto à pertinência do acolhimento, Caps, UAA e o usuário montam um PTS, que pode incluir atividades no Caps, ações referentes à documentação, cuidados clínicos, trabalho, lazer, educação, entre outros, sempre de acordo com a singularidade do caso. A partir da indicação e do acompanhamento do caso, novas propostas podem ser construídas durante o próprio acolhimento. Entende-se que, durante o período de acolhimento, o cuidado é compartilhado entre Caps e UAA. Na hipótese de não haver consenso quanto à indicação para o acolhimento, novas reuniões para discussão do caso são realizadas.

A entrada no acolhimento não necessariamente se dá quando o caso é discutido. Porém, a partir da discussão, pode-se pensar e definir quais serão as estratégias de aproximação entre usuário e UAA, a forma de entrada no acolhimento e quando se dará essa entrada. As principais indicações apontadas pela equipe para ingresso na UAA são: laços familiares esgarçados, necessidade de um período para se restabelecer após uso mais intenso de substâncias e dificuldades relacionadas ao território de origem do usuário.

Sobre o encerramento do acolhimento, deve-se respeitar o processo de cada usuário. Porém, tanto a Portaria ${ }^{\circ} 121 / 2012$ quanto a Nota Técnica $n^{\circ} 41 / 2013$, do Ministério da Saúde, destacam a importância da atenção ao tempo de permanência, tendo como parâmetro o limite máximo de seis meses. Os referidos documentos apontam que o PTS de cada usuário deve incluir, além das ações a serem desenvolvidas, o tempo de permanência previsto ${ }^{13,18}$. Foi observado que a saída de um usuário do acolhimento está relacionada à realização do que foi proposto em seu início. Assim, o PTS pode incluir a dimensão de tempo, mas não se reduz a ele.

A saída do acolhimento configura-se como um processo, de forma que a saída não seja vivenciada de forma abrupta. Nesse período, o vínculo entre o usuário e a UAA se fortalece, 
e são pensadas estratégias que visam gradativamente à inclusão de outros atores, a fim de promoverem a reinserção do usuário na comunidade.

Na dinâmica da UAA, destacam-se as atividades internas e externas desenvolvidas, que, em sua maioria, estão relacionadas à organização da casa, à articulação da rede de suporte do usuário no território e à reinserção social dos acolhidos.

A casa tem uma movimentação que varia de acordo com os usuários em acolhimento e seus PTSs, bem como com a inserção de cada acolhido no território. Ao longo do dia, alguns estudam, trabalham e frequentam seus Caps de referência. No período diurno, é realizada a maioria das ações externas propostas em cada PTS, sendo incentivada a participação em atividades externas, como estratégia para manter e ampliar a rede de cada um.

As atividades coletivas internas acontecem com maior frequência nos finais de semana, ou no horário noturno, visando a facilitar a participação dos acolhidos. A convivência entre estes e a equipe resulta em atividades coletivas espontâneas, que são viabilizadas pela UAA. A esse respeito, a pesquisa identificou relatos da realização de churrascos e festas, geralmente em datas comemorativas, como aniversários, Natal e fim de ano.

Ainda, sobre a dinâmica diária da UAA, observou-se que algumas normas foram construídas ou modificadas a partir da própria experiência de funcionamento da unidade, como, por exemplo, o fluxo diário de circulação no território. Os acolhidos podem sair sozinhos da unidade, seja para ações combinadas no PTS ou por qualquer outro motivo por que desejem sair, sempre mediante comunicação à equipe do horário de retorno. $\mathrm{O}$ retorno deve ocorrer até as 19 horas, e qualquer saída após esse horário dever ser combinada com a equipe técnica. Essas orientações buscam estimular a comunicação entre acolhidos e profissionais, assim como organizar a rotina da casa.

Em determinadas situações, não é indicado que o acolhido saia à noite, e, caso ele insista, é orientado a retornar na manhã do dia seguinte. Quando, ainda assim, o usuário volta durante a noite ou madrugada, ele é atendido e avaliado. Se, naquele momento, não for possível permanecer na UAA, em função de uma particular situação (de intoxicação, por exemplo), o usuário é acompanhado até o Caps AD para aguardar atendimento.

Um aspecto importante dos cuidados diários refere-se às questões clínicas e à articulação com unidades básicas de saúde. Os acolhidos que apresentam demandas clínicas são orientados a ir ao serviço de atenção básica de seu endereço de referência. Em alguns casos, o acolhido é orientado a ir ao serviço da atenção básica que cobre o endereço da UAA. Enquanto o usuário estiver na UAA, a equipe o acompanha em seu percurso com os cuidados clínicos.

Outra dimensão do cotidiano da unidade refere-se às ferramentas de respostas dos profissionais aos desafios trazidos por situações cotidianas na UAA. Ou seja, os caminhos e manejos que a equipe aciona a fim de garantir a continuidade e o desenvolvimento do PTS. Por exemplo, em ocasiões em que a equipe percebe que o acolhido está sob efeito de alguma substância, ou até mesmo quando o encontra fazendo uso dentro da unidade, é solicitado que ele descarte a substância, tendo em vista que não é permitido portar nem usar drogas dentro da unidade (a não ser tabaco e as medicações prescritas). É realizado atendimento para avaliar como o acolhido está e compreender o que o levou a tal ação. Caso o acolhido esteja muito alterado ou intoxicado, é acompanhado ao Caps AD para atendimento e cuidados específicos. Caso contrário, ele segue na UAA.

Entre os manejos de situações comuns nessa UAA, destacam-se: escutar, conversar, realizar acordos, orientar, acomodar o acolhido em outro ambiente para evitar brigas, avaliar uso da medicação, compartilhar com o Caps AD questões relacionadas à intoxicação ou ao PTS, acompanhar na circulação pelo território. Essas são ferramentas cuja potencialidade se 
amplia a partir de uma convivência diária do usuário com a equipe e do acompanhamento do percurso de cada um. E são elas que dão particular significado à UAA e a diferenciam de instituições centradas no confinamento e que desconsideram a subjetividade, como as CTs.

A UAA é um serviço residencial, e, como tal, visa a ser um espaço projetado para acolhimento, hospitalidade e convivência. Vale destacar que a possibilidade de habitar e o enriquecimento das redes sociais são eixos centrais na proposição de 'reabilitação como cidadania'19.

O habitar está relacionado a um grau de apropriação do espaço onde se vive, ao sentimento de pertencimento e à contratualidade. Por isso, compreende-se que, na UAA, os atos da vida cotidiana, como comer, falar, dormir, caminhar, trabalhar, trocar afetos e mercadorias, acontecem em lugares e tempos diferentes para cada um. Em instituições de internação hospitalar ou em comunidades terapêuticas, essa cotidianidade não é validada. Para cada ato existe uma regra, e a regulação não abre possibilidade para que o usuário se aproprie do espaço de forma individual. Em tais situações, não se habita, se 'está em'. Onde não há meios de exercer a singularidade, existe a rigidez nas normas de convivência e uma série de proibições, a partir de ações voltadas para a generalização e a manutenção da condição de tutela ${ }^{20}$.

A apropriação é um processo psicológico de ação e intervenção sobre um espaço, a fim de transformar e personalizar. Esse sistema de influência sobre os lugares envolve as formas e os tipos de intervenção sobre ele que se traduzem em relações de posse e apego. A apropriação exprime uma forma de ocupação do espaço e

consiste em produzir diversidade ao investir o espaço de intenções e atos que permitem ao indivíduo sobreviver à banalidade do cotidiano e dar-se a si mesmo uma identidade ${ }^{17(83)}$.

A UAA demonstra um tipo de organização flexível que possibilita a expressão de alguns mecanismos de apropriação por parte dos acolhidos. Existem algumas regras de convivência na unidade, assim como em todo espaço social. Contudo, é possível aos acolhidos algum grau de intervenção para estruturar o espaço de acordo com seus próprios critérios.

Já a contratualidade implica a abertura de espaços de negociação, ou seja, aumentar possibilidades de trocas. As instituições formais e informais da comunidade representam recursos, com infinitas possibilidades de articulações entre serviço, usuário e comunidade, que são capazes de produzir sentido e contratualidade ${ }^{20}$.

Considerando-se a organização diária da unidade, é possível observar importantes pontos de oposição entre as UAAs e as CTs. A UAA, como apresentado nesse eixo, garante o cuidado singularizado e em liberdade, seguindo a lógica da redução de danos e da atenção psicossocial. Enquanto isso, as CTs, de acordo com o Relatório da Inspeção Nacional em Comunidades Terapêuticas (201710) e o Perfil das Comunidades Terapêuticas Brasileiras ${ }^{\mathbf{1 2}}$, têm seu funcionamento baseado na imposição de abstinência, no isolamento, na restrição do convívio social e defende uma política de internação prolongada.

Diante da baixa assistência de serviços públicos voltados para os usuários de drogas, a população tende a buscar recursos próprios para lidar com essas questões. Nessa circunstância, as CTs são uma resposta possível da população, e, embora desempenhem função de suporte social, também apresentam inúmeros problemas de violação aos direitos humanos, assim como rigidez das normas, desconsiderando um cuidado que respeite a singularidade de cada um²1.

\section{Relação com o território}

Parte importante do trabalho realizado durante o acolhimento na UAA é a aproximação com as organizações e os atores sociais do território. Inclui-se aqui o diálogo com os moradores da região, os comerciantes, a associação de moradores e outros agentes, de forma a promover a reinserção do usuário na comunidade. 
Essa aproximação ocorre em situações nas quais o profissional acompanha o acolhido em atividades no território, de acordo com o PTS, ou a partir de uma avaliação feita pela equipe. Entre tais situações, destacam-se: idas a serviços de atendimento público, como o Centro de Referência de Assistência Social (Cras), o Instituto Nacional do Seguro Social (INSS) e consultas e/ou realização de exames junto à atenção básica; assuntos de ordem pessoal, como idas ao banco, procura de local de moradia para alugar, visitas a filhos em abrigo e enterro de amigos ou parentes do acolhido. São realizadas, ainda, saídas com os acolhidos para atividades de lazer e cultura, como blocos de carnaval, eventos em museus, passeios na praia, participação na festa junina do Caps e teatros.

Destaca-se ainda, na relação com o território, a articulação com a rede intersetorial, especialmente saúde, assistência social, cultura, justiça e educação. É um trabalho que ocorre, por exemplo, quando a equipe, representada por um ou dois profissionais, participa de reuniões e fóruns, como: reunião de território do Cras, Fórum Estadual AD, Fóruns de Saúde Mental, Fórum de Geração de Renda e Cultura e Supervisão do Caps AD.

Os profissionais entrevistados apontam que, ao longo dos anos de funcionamento da UAA, a comunidade passou a enxergar a unidade de forma diferente. No início, a comunidade estava preocupada que um serviço voltado para usuários de drogas no bairro pudesse aumentar o número de usuários circulando na região. Atualmente, a concepção que a comunidade tem sobre a UAA é outra, e alguns profissionais relatam que são abordados por moradores da região que solicitam informações de como iniciar o tratamento. Um dos profissionais observou que essa mudança ocorreu justamente devido à inserção das unidades de tratamento para usuários de álcool e drogas (Caps AD e UAA) no território.

A característica territorial da UAA aumenta as possibilidades de trocas, assim como de articulações com diferentes atores da comunidade, o que também gera questionamentos e conflitos de diversas ordens. Contudo, é importante destacar que conflitos podem ser formas de criar diálogos, repensar práticas e construir novas respostas. Saraceno 20 observa que o conflito em si também é recurso para o serviço de saúde, e que, por isso, faz-se importante pensar na criação de condições para a sua expressão e para sua superação. Não o seu silenciamento.

É comum pessoas pedirem informações, chegando até a confundirem a UAA com o Caps AD. Uma das profissionais entrevistadas conta que, de vez em quando, moradores que a conhecem a abordam para falar a respeito de algum usuário, mesmo que ele não esteja mais em acolhimento. A profissional afirma que uma boa relação da UAA com a comunidade favorece as articulações com o território. Por isso, identifica a importância de estar nas ruas, nas praças, sempre se comunicando com as pessoas do entorno.

O trabalho da unidade de acolhimento não se limita ao espaço interno, e apresenta como importante característica a construção de possibilidades com o território. Esse convívio com a comunidade do entorno é necessário para estabelecer e manter uma relação que visa a potencializar a rede de parcerias da UAA, ampliar as formas de cuidado aos usuários, bem como se colocar como um ponto de referência para a comunidade no que diz respeito ao cuidado relacionado ao uso de drogas.

Outra forma pela qual a comunidade acessa a UAA é para comunicar ou avisar sobre algum acontecimento que acredite ser de importância para os profissionais da unidade.

Uma breve ilustração da relevância dessa relação pode ser observada em um caso no qual a vizinha da UAA foi avisar à equipe que um acolhido estava numa rua, a duas quadras da unidade, alcoolizado e se arriscando ao passar na frente dos carros. A equipe pôde, então, se organizar para que dois profissionais fossem até o local indicado pela vizinha. Quando chegaram ao local, havia uma ambulância, que ajudou na avaliação inicial e na condução do usuário até $\mathrm{o}$ Caps $\mathrm{AD}$, onde foram realizados 
procedimentos para desintoxicação, dando seguimento aos cuidados.

Importante pontuar que, embora a UAA estudada esteja vinculada ao Caps $\mathrm{AD}$ de referência, recebe usuários de todas as regiões do município, chegando, inclusive, a acolher usuários de outros municípios do estado, desde que a distância geográfica seja levada em consideração no momento da indicação e na construção do PTS. A UAA tem em sua área de cobertura aproximadamente um milhão de habitantes, além de dar suporte a casos de outras regiões. Em situações assim, é priorizado que as ações do PTS ocorram onde o usuário possua vinculação, no sentido de manter os laços e as relações já estabelecidos, observando a singularidade de cada caso. Desse modo, a UAA se articula tanto com Caps quanto com Caps $\mathrm{AD}$ de várias regiões do município. Essa direção de trabalho foi sendo desenhada ao longo dos anos e a partir das demandas dos demais serviços da Raps.

Somente o Caps pode indicar usuários para acolhimento na UAA, o que faz com que a maioria das articulações realizadas seja estabelecida com esse serviço. A relação com os demais componentes da rede intersetorial faz-se a partir da demanda de cada caso acolhido, de forma que essa interlocução é mais bem estabelecida com os serviços da área de cobertura da UAA. Os casos acolhidos de outras regiões, embora tenham articulação com a UAA, dependem mais do Caps de referência do acolhido.

O acolhimento na UAA proporciona lugares de convivência e promove o resgate de vínculos, o que implica que não seja um espaço autorreferente, fechado em si mesmo, fazendo-se contrário a modelos de internação e confinamento. Por meio da oferta de outras formas de convivência e outras formas de negociação, o usuário acolhido na UAA encontra possibilidade de novos arranjos subjetivos.

Frare $^{22}$ destaca que o encontro com os outros, com as regras de convivência e com os contratos sociais é o disparador de uma necessidade de organização subjetiva. Entende-se, assim, que o acolhimento na UAA e o seu modo de lidar com os acolhidos nas situações cotidianas na casa e na cidade abrem possibilidades de outras formas de relação com o uso de drogas, com o tratamento, com os familiares, com o bairro, entre outros.

\section{Considerações finais}

O uso prejudicial de drogas é um campo permeado por muitas disputas - sejam políticas, acadêmicas ou técnicas -, que vêm se intensificando em meio a movimentos de desmonte da atual política pública de saúde mental. A falta de serviços extra-hospitalares e a dificuldade no acesso ao sistema de saúde contribuem para que outros atores, que não a saúde, ganhem espaço. Importantes discussões têm sido levantadas a respeito do apoio e do financiamento que as CTs têm recebido. Essas instituições, em geral, baseiam-se no isolamento e na imposição da abstinência para o usuário de drogas e se utilizam da problemática do uso de drogas para legitimar a internação prolongada, típica da cultura manicomial.

A UAA é um serviço de base territorial do SUS que faz frente à questão das internações voltadas para os usuários de álcool e outras drogas. Na disputa entre modelos de tratamento, as UAAs surgem em consonância com os princípios da Reforma Psiquiátrica Brasileira. Desse modo, pode-se afirmar que as UAAs foram criadas para responder à questão prática de locais físicos onde acolher pessoas com necessidades decorrentes do uso de álcool e/ou outras drogas, seguindo a direção do cuidado em liberdade.

Ao longo dos anos de funcionamento, a equipe da UAA estudada desenvolveu várias discussões, desde a compreensão teórica sobre redução de danos, atenção psicossocial, reforma psiquiátrica até questões de cunho mais prático, como normas e regras internas, o que dificultava ou ajudava os usuários acolhidos e facilitava ou não a melhoria de sua qualidade de vida, entre muitos outros 
tópicos relevantes. Nesse processo, a equipe foi desenvolvendo sua forma de atuação junto aos usuários, à comunidade e à rede intersetorial. É um processo contínuo, que segue em andamento, com reconhecimento de avanços e a clareza de que há ainda muito a ser feito.

Este é um momento de extrema importância para uma avaliação do serviço, da experiência da UAA e dos caminhos que foram traçados, pois faz-se necessário pensar em estratégias que garantam o cuidado em liberdade no território e a redução de danos como direção desse cuidado. O contexto geral de crise econômica e política e os retrocessos nos direitos e nas políticas sociais convocam a pensar em táticas de resistência.

A UAA implica a criação das mais diferentes estratégias para o tratamento das questões relacionadas ao uso de álcool e drogas, uma vez que lida com as questões do 'habitar' não somente uma casa, mas também a cidade - daqueles afetados mais diretamente pela desigualdade e pela marginalização. Sua característica territorial busca o enriquecimento da rede social do usuário e o aumento de possibilidades de trocas, assim como articulações com diferentes atores da comunidade, gerando debates e questionamentos de todas as ordens.
Esta pesquisa se propôs a desenvolver um estudo de caso exploratório sobre uma UAA, com intuito de fornecer maior qualidade e contextualização à produção de conhecimento sobre ela. Dessa forma, acredita-se ter sido cumprido o objetivo maior desta pesquisa, que contribuiu para dar visibilidade a esse tipo de serviço de saúde.

Dada a complexidade do objeto, diversos pontos levantados neste estudo necessitam ser aprofundados, o que ressalta a importância da continuidade de estudos relativos à temática, principalmente em um cenário de disputas no qual discursos manicomiais e proibicionistas vêm ganhando espaço.

\section{Colaboradoras}

Almeida ALM (0000-0003-1289-6396)* contribuiu para concepção, planejamento, análise e a interpretação dos dados; para elaboração da revisão crítica do conteúdo; e para aprovação da versão final do manuscrito. Cunha MB (0000-0001-7509-9138)* contribuiu para concepção; para elaboração da revisão crítica do conteúdo; e para aprovação da versão final do manuscrito. 


\section{Referências}

1. Vaissman M, Ramôa M, Serra ASV. Panorama do Tratamento dos usuários de drogas no Rio de Janeiro. Saúde debate. 2008; 32(78-79-80):121-132.

2. Passos EH, Souza TP. Redução de Danos e saúde pública: construções alternativas à política global de "guerra as drogas". Psicol. Soc. 2011; 23(1):154-162.

3. Brasil. Lei $n^{\circ} 11.343$, de 23 de agosto de 2006. Institui o Sistema Nacional de Políticas Públicas sobre Drogas - Sisnad; prescreve medidas para prevenção do uso indevido, atenção e reinserção social de usuários e dependentes de drogas; estabelece normas para repressão à produção não autorizada e ao tráfico ilícito de drogas; define crimes e dá outras providências. Dispõe sobre a proteção e os direitos das pessoas portadoras de transtornos mentais e redireciona o modelo assistencial em saúde mental. Diário Oficial da União. 24 Ago 2006.

4. Neves AGS. As políticas públicas de álcool e outras drogas no Brasil: uma análise da construção política de 1990 a 2015 [tese]. Rio de Janeiro: Fundação Oswaldo Cruz, Escola Nacional de Saúde Pública Sergio Arouca; 2018. 123 p.

5. Brasil. Lei $n^{0} 13.840$, de 05 de junho de 2019. Altera as Leis nos 11.343, de 23 de agosto de 2006, 7.560, de 19 de dezembro de 1986, 9.250, de 26 de dezembro de 1995, 9.532, de 10 de dezembro de 1997, 8.981, de 20 de janeiro de 1995, 8.315, de 23 de dezembro de 1991, 8.706, de 14 de setembro de 1993, 8.069, de 13 de julho de 1990, 9.394, de 20 de dezembro de 1996, e 9.503, de 23 de setembro de 1997, os Decretos-Lei nos 4.048, de 22 de janeiro de 1942, 8.621, de 10 de janeiro de 1946, e 5.452, de $1^{\circ}$ de maio de 1943, para dispor sobre o Sistema Nacional de Políticas Públicas sobre Drogas e as condições de atenção aos usuários ou dependentes de drogas e para tratar do financiamento das políticas sobre drogas [internet]. [acesso em 2019 jul 5]. Disponível em: http://www.planalto. gov.br/ccivil_03/_ato2019-2022/2019/lei/L13840. htm.
6. Comissão Intergestores Tripartite. Resolução $n^{0} 32$, de 14 de dezembro de 2017. Estabelece as diretrizes para o fortalecimento da Rede de Atenção Psicossocial (RAPS). Diário Oficial da União. 22 Dez 2017.

7. Brasil. Lei $\mathrm{n}^{0} 10.216$, de 06 de abril de 2001. Dispõe sobre a proteção e os direitos das pessoas portadoras de transtornos mentais e redireciona o modelo assistencial em saúde mental. Diário Oficial da União. 9 Abr 2001.

8. Conselho Nacional de Políticas sobre Drogas. Resolução $n^{\circ}$ 1, de 9 de março de 2018. Define as diretrizes para o realinhamento e fortalecimento da PNAD - Política Nacional sobre Drogas, aprovada pelo Decreto 4.345, de 26 de agosto de 2002. Diário Oficial da União. 13 Mar 2018.

9. Vasconcelos EM. Reforma psiquiátrica, tempos sombrios e resistência: diálogos com o marxismo e o serviço social. Campinas: Papel Social; 2016.

10. Conselho Federal de Psicologia. Relatório da Inspeção Nacional em Comunidades Terapêuticas - 2017/ Conselho Federal de Psicologia; Mecanismo Nacional de Prevenção e Combate à Tortura; Procuradoria Federal dos Direitos do Cidadão/Ministério Público Federal. Brasília, DF: CFP; 2018.

11. Amarante P, Nunes MO. A reforma psiquiátrica no SUS e a luta por uma sociedade sem manicômios. Ciênc. Saúde Colet. 2018; 23(6):2067-2074.

12. Instituto de Pesquisa Econômica Aplicada. Nota Técnica - Número 21: Perfil das Comunidades Terapêuticas Brasileiras. Brasília, DF: IPEA; 2017.

13. Brasil. Ministério da Saúde. Portaria $n^{\circ} 121$, de 25 de janeiro de 2012. Institui a Unidade de Acolhimento para pessoas com necessidades decorrentes do uso de Crack, Álcool e Outras Drogas (Unidade de Acolhimento), no componente de atenção residencial de caráter transitório da Rede de Atenção Psicossocial. Diário Oficial da União. 27 Jan 2012. 
14. Lima EMFA, Yasui S. Territórios e sentidos: espaço, cultura, subjetividade e cuidado na atenção psicossocial. Saúde debate. 2014; (38):593-606.

15. Vasconcelos EM. Complexidade e Pesquisa Interdisciplinar: epistemologia e metodologia operativa. Petrópolis: Vozes; 2002.

16. Becker H. Método de Pesquisas em Ciências Sociais. São Paulo: Hucitec; 1993.

17. Fischer Gustave-N. Psicologia Social do Ambiente. Lisboa: Instituto Piaget; 1994.

18. Brasil. Ministério da Saúde, Secretaria de Atenção à Saúde, Departamento de Articulação de Rede de Atenção. Nota Técnica no 41, de 2013. Esclarecimentos e Orientações a respeito da republicação da Por$\operatorname{taria~}^{\circ} 121$, de 25 de janeiro de 2012 , republicada no Diário Oficial da União, 21 Maio 2013, nº 96, seção 01, página 41. [Brasília] 2013. [acesso em 2019 fev 2]. Disponível em: https://portalarquivos2.saude.gov. br/images/pdf/2015/marco/10/Nota-T--cnica-Portaria-121-2012.pdf.
19. Assis JT, Barreiros CA, Jacinto ABM, et al. Política de saúde mental no novo contexto do Sistema Único de Saúde: regiões e redes. Rev. Divulg. Saúde debate. 2014; (52):88-113. [acesso em 2018 mar 12]. Disponível em: http://cebes.org.br/site/wp-content/uploads/2014/12/Divulgacao-52.pdf.

20. Saraceno B. Libertando Identidades. Da reabilitação social à cidadania possível. 2. ed. Belo Horizonte: Te Corá Editora; 2001.

21. Vasconcelos EM, Cavalcante R. Religiões e o paradoxo apoio social/intolerância, e implicações na política de drogas e comunidades terapêuticas. São Paulo: Hucitec; 2019

22. Frare AP. No litoral da casa e do serviço: a psicanálise no serviço residencial terapêutico [tese]. Rio de Janeiro: Programa de Pós-Graduação em Psicanálise da Universidade do Estado do Rio de Janeiro; 2012. $170 \mathrm{p}$.

Recebido em 02/03/2020 Aprovado em 05/11/2020 Conflito de interesses: inexistente

Suporte financeiro: não houve 